\title{
Antidepressants in urban wastewater treatment plant: occurrence, removal and risk assessment
}

\author{
Aydin S., Aydin M.E., Tekinay A.* and Kiliç H. \\ Necmettin Erbakan University, Environmental Engineering Department, Konya-Turkey \\ Received: 16/06/2016, Accepted: 14/11/2016, Available online: 07/03/2017 \\ *to whom all correspondence should be addressed: \\ e-mail: atekinay@konya.edu.tr
}

\section{Abstract}

In this study, an analytical methods for determination of antidepressants including (diazepam (DZP), lorazepam (LZP), carbamazepine (CBZ), fluoxetine (FLU)) was developed. The concentration of antidepressants was monitored in Konya Urban Wastewater Treatment Plant influent and effluent samples for one years. Environmental risk assessment was performed with detected concentration with treatment plant effluent wastewater by hazard quotient (HQ) methods. Oasis HLB cartridges with SPE system was used for extraction of wastewater samples. The effect of sample volume and $\mathrm{pH}$, different analyte concentration, pretreatment and matrix on efficiency of cartridges were optimized. Quantitative analyses of the target compounds were performed by LC/MS-MS system. Recoveries of antidepressant compounds from fortified wastewater were over $87 \%$ for three different fortification levels. The limits of detection were determined between 0.006 and $0.118 \mathrm{ng} \mathrm{l}^{-1}$. CBZ, FLU and LZP concentration in influent varied from 6.3 to $135.6 \mathrm{ng} \mathrm{l}^{-1},<\mathrm{dl}$ to $2.6 \mathrm{ng} \mathrm{l}^{-1},<\mathrm{dl}$ to $4.8 \mathrm{ng} \mathrm{l}^{-1}$, respectively, while DZP was not detected. CBZ, DZP, FLU and LZP concentrations in the effluent was determined as $<\mathrm{dl}-245.1 \mathrm{ng} \mathrm{l}^{-1},<\mathrm{dl}-0.21 \mathrm{ng} \mathrm{l}^{-1},<\mathrm{dl}-2.7 \mathrm{ng} \mathrm{l}^{-1}$, $<\mathrm{dl}-2.2 \mathrm{ng} \mathrm{l}^{-1}$, respectively. Antidepressants were generally removed in January, February, and August. The high removal was determined for CBZ compounds as \%100 at January. The low removal was determined for FLU compounds as $\% 2.4$ at January.

While the $H Q$ values for DZP, LZP, CBZ were determined below 0.1 which means insignificant risk to aquatic organisms, HQ values for FLU determined above 0.1 which means low risk to aquatic organism

Key words: Antidepressant, removal, risk assessment, wastewater.

\section{Introduction}

Nowadays, pharmaceutically active substances have become of increasing concern due to their potential toxic environmental effects. These compounds have been recently classified as emerging pollutants. Pharmaceuticals are increasingly determined in surface waters, ground waters, and drinking water. Because, they are not removed in conventional wastewater treatment plants. The main resources of pharmaceuticals in environment are metabolic waste of patients and manufacturing processes. Antidepressants are a group of pharmaceuticals commonly used. Antidepressants are used to treat the symptoms of depression, sleep and eating disorders, alcohol and drug abuse, panic, chronic pain and post-traumatic stress disorder (Santoke et al., 2012).

12 of the top 100 prescribed pharmaceuticals were antidepressants, in North America in 2007 (Calisto and Esteves, 2009). According to data of 2012 from International Marketing Services (IMS), consumption of antidepressants in Turkey in 2003 and 2008 was 14238 and 31302 million boxes, respectively. The consumption ratio has increased $120 \%$. In 2012, the consumption ratio has increased $260 \%$ and 36881 million boxes antidepressants were consumed in Turkey.

Antidepressants are not completely metabolized by the human body and they are excreted the unchanged parent compound, metabolites or conjugates (Heberer, 2002). Over 3000 different pharmaceuticals used in human and veterinary medicines can be found in aquatic environments (Richardson and Ternes, 2005; Fent et al., 2006). Antidepressants are one of the important concerns for non-target organism in aquatic and terrestrial environment because they can affect the endocrine system and the nervous system (Van der Ven et al., 2006).

Carbamazepine, diazepam, fluoxetine, lorazepam, paroxetine are commonly detected in environmental media. Presence of antidepressants in environmental media has also been reported in some studies. For example, diazepam was determined over $10 \mathrm{ng} \mathrm{l}^{-1}$ in river and potential drinking water, and was found first time less than $1 \mu \mathrm{g} \mathrm{I}^{-1}$ in wastewater treatment plant effluent in 1981. Ternes et al., (2001) determined diazepam in wastewater treatment plant effluent as $0.053 \mu \mathrm{g} \mathrm{I}^{-1}$ and in river and stream as $0.033 \mathrm{\mu g} \mathrm{I}^{-1}$. Paroxetine was found 2.1-3.0 $\mathrm{ng} \mathrm{l}^{-1}$ at the point discharge of the wastewater treatment plant in the USA (Schultz and Furlong, 2008). Kolpin et al., (2002) determined fluoxetine at $0.012 \mathrm{\mu g} \mathrm{l}^{-1}$ concentration in surface water in USA. Pharmaceutical compounds are 
persistent in environment. Moreover, their removal is difficult in the conventional wastewater treatment plants. Advanced treatment methods can provide high removal efficiency for degradation of resistant pharmaceutical compounds. Ternes et al., (2005) reported that diazepam removed between $50-90 \%$ by advanced oxidations process. Radjenovic et al., (2007) reported paroxetine removed $89.7 \%$ by membrane bioreactor.

The objectives of this paper, method using SPE and LC$\mathrm{MS} / \mathrm{MS}$ was developed to determinate four antidepressants (diazepam (DZP), lorazepam (LZP), carbamazepine (CBZ), fluoxetine (FLU)) in wastewater. The antidepressants were investigated in terms of occurrence and removal in the influent and effluent of a WWTP in Konya, Turkey over one year. Also potential risk was evaluated with detected concentration in the effluent.

\section{Material and methods}

\subsection{Materials and chemicals}

DZP, LZP, CBZ, FLU standards were provided from Fluka. Stock solutions of $1000 \mathrm{mg} \mathrm{ml}^{-1}$ of each antidepressants were prepared in methanol and stored at $-20{ }^{\circ} \mathrm{C}$. Acetonitrile (ACN), methanol, hydrochloric acid (\%37), formic acid (\%98), $\mathrm{Na}_{2}$ EDTA were purchased from Merck. Glass fiber filters $(1.2 \mu \mathrm{m})$ were obtained from Whatman. Nylon membrane filters $(0.45 \mu \mathrm{m})$ were obtained from Sartorius. Oasis HLB cartridges $(60 \mathrm{mg}, 3 \mathrm{ml}$ ) were provided from Waters Corporation.

\subsection{Sample Collection and Preparation}

For a year, 24-h composite samples of the influent and effluent of Konya wastewater treatment plant in Turkey. Wastewater samples were filtered through $1.2 \mu \mathrm{m}$ glass fiber filters followed by filtration with $0.45 \mu \mathrm{m}$ nylon membrane filters. $0.1 \mathrm{M} \mathrm{Na}{ }_{2}$ EDTA was added to the samples. Samples were either extracted immediately or kept at $4{ }^{\circ} \mathrm{C}$ until extraction.

\subsection{Liquid Chromatography-Tandem Mass Spectrometry Analysis}

Liquid chromatography (LC) was performed using an Agilent 1260 LC/MS/MS system that operated positive ion mode electrospray ionization (ESI). Antidepressants were separated on an Agilent Poroshell 120 EC-C18 (3.0x100 $\mathrm{mm}, 2.7 \mu \mathrm{m})$ column. Binary gradient made of $\mathrm{A}(0.1 \%$ formic acid and $5 \mathrm{mM}$ ammonium formate in ultrapure water), and eluent B (methanol) was used at a flow rate of $0.6 \mathrm{ml} \mathrm{min} \mathrm{m}^{-1}$. The gradient program began with a hold for 1 min at $90 \%$ of $A$ and $10 \% \mathrm{~B}$, followed by a 3 min gradient to $30 \%$ of $B$, then a 8 min gradient to $70 \%$ and a further 2 min gradient to $95 \%$ of eluent $B$ and it was held constant at $95 \%$ for $2 \mathrm{~min}$. The column temperature was at $35{ }^{\circ} \mathrm{C}$ and the volume of injection was $2 \mu \mathrm{l}$.

\subsection{Solid Phase Extraction (SPE)}

SPE method with Oasis HLB cartridge was used for extraction and clean-up of the samples. SPE was performed with a J.T. Baker 24 port vacuum manifold at flow rates $1 \mathrm{ml} \mathrm{min}-1$. The cartridge was conditioned with $2 \times 2.5 \mathrm{ml}$ methanol followed by $2 \times 2.5 \mathrm{~mL}$ ultrapure water at $\mathrm{pH}$ of samples. Cartridge was washed with $2 \times 2.5 \mathrm{ml}$ ultrapure water and it was dried with air under vacuum for $5 \mathrm{~min}$. Antidepressants were eluted with $4 \times 2.5 \mathrm{ml}$ of methanol. Extracts were evaporated until almost dryness and reconstituted with $1 \mathrm{ml}$ of methanol/water $(50 / 50, \mathrm{v} / \mathrm{v})$. This procedure was applied all SPE experiments. The effect of sample volume (100 and $200 \mathrm{ml}$ ) and $\mathrm{pH}$ (2.5 and 7.0), different analyte concentration $\left(100,500,1000 \mathrm{ng} \mathrm{l}^{-1}\right)$, pretreatment $(0.45 \mu \mathrm{m}$ nylon membrane filter, $1.2 \mu \mathrm{m}$ glass fiber filters) and matrix (ultrapure water, influent and effluent) on efficiency of cartridges was optimized.

\section{Results}

\subsection{LC/MS-MS Optimization}

Table 1 shows retention time of antidepressant compounds for Poroshell 120 EC-C18 column and ions selected for MS/MS analysis. Table 2 also shows LOD, LOQ, linearity, for antidepressant compounds obtained with LCMS/MS systems. Analytical curves were drawn using 9 points in the concentration range of $2-500 \mathrm{ng} \mathrm{l}^{-1}$. The regression coefficients (R2) for all studied PCBs were between 0.993 and 0.998 . The limits of detection (LODs), based on a signal-to-noise ratio $(\mathrm{S} / \mathrm{N})$ of 3, ranged from $0.006 \mu \mathrm{g} \mathrm{l}^{-1}$ for FLU to $0.118 \mu \mathrm{gl}^{-1}$ for LZP.

Table 1. Retention time and $\mathrm{m} / \mathrm{z}$ values of antidepressant compounds determined by LC-MS/MS system

\begin{tabular}{ccl}
\hline Compounds & \multicolumn{1}{c}{ RT } & \multicolumn{1}{c}{$\mathbf{~ m / z}$} \\
\hline CBZ & 12.388 & $237[\mathrm{M}+\mathrm{H}]^{+}$ \\
\hline LZP & 13.490 & $321-290[\mathrm{M}+\mathrm{H}]^{+}$ \\
\hline FLU & 13.672 & $310[\mathrm{M}+\mathrm{H}]^{+}$ \\
\hline DZP & 14.636 & $285-154[\mathrm{M}+\mathrm{H}]^{+}$ \\
\hline
\end{tabular}

Table 2. LOD, LOQ, linear response range, linearity values of antidepressant compounds determined by LC-MS/MS system

\begin{tabular}{|c|c|c|c|c|}
\hline Compounds & $\begin{array}{c}\text { LOD } \\
\left(\mu \mathrm{g} \mathrm{I}^{-1}\right)\end{array}$ & $\begin{array}{c}\text { LOQ } \\
\left(\mu \mathrm{g} \mathrm{I}^{-1}\right)\end{array}$ & $\mathbf{R}^{2}$ & $\begin{array}{c}\text { Linear range } \\
\left(\mu \mathrm{g}^{-1}\right)\end{array}$ \\
\hline CBZ & 0.034 & 0.114 & 0.9933 & $2-500$ \\
\hline DZP & 0.026 & 0.089 & 0.9948 & $2-100$ \\
\hline FLU & 0.006 & 0.021 & 0.9954 & $2-500$ \\
\hline LZP & 0.118 & 0.393 & 0.9980 & $2-500$ \\
\hline
\end{tabular}

\subsection{Optimization of SPE Procedure}

The aim of the optimization procedure was to improve the extraction efficiency with minimum sample volume and time consumption during the extraction. Therefore, a careful optimization of the extraction parameters would be necessary in order to get satisfactory results. $\mathrm{pH}$ and sample volume effect on efficiency of cartridges are given in Figure 1. While the recoveries of antidepressants were determined between 92 and 102\% (SD < 6) at pH 2.5 the recoveries were determined between 91 and 103\% (SD < 8) at $\mathrm{pH}$ 7. The recovery values obtained for different $\mathrm{pH}$ values were not significantly different $(p>0.05)$. Therefore, the optimum sample $\mathrm{pH}$ was chosen as $\mathrm{pH}$ 7. The extraction efficiencies for antidepressant compounds increased with increasing of the volume of sample from $100 \mathrm{ml}$ (89-95\%, $\mathrm{SD}<6)$ to $200 \mathrm{ml}(91-103 \%, \mathrm{SD}<8)$. The recovery values obtained for different sample volume were significantly 
different $(p<0.05)$. Therefore, the optimum sample volume was determined as $200 \mathrm{ml}$.

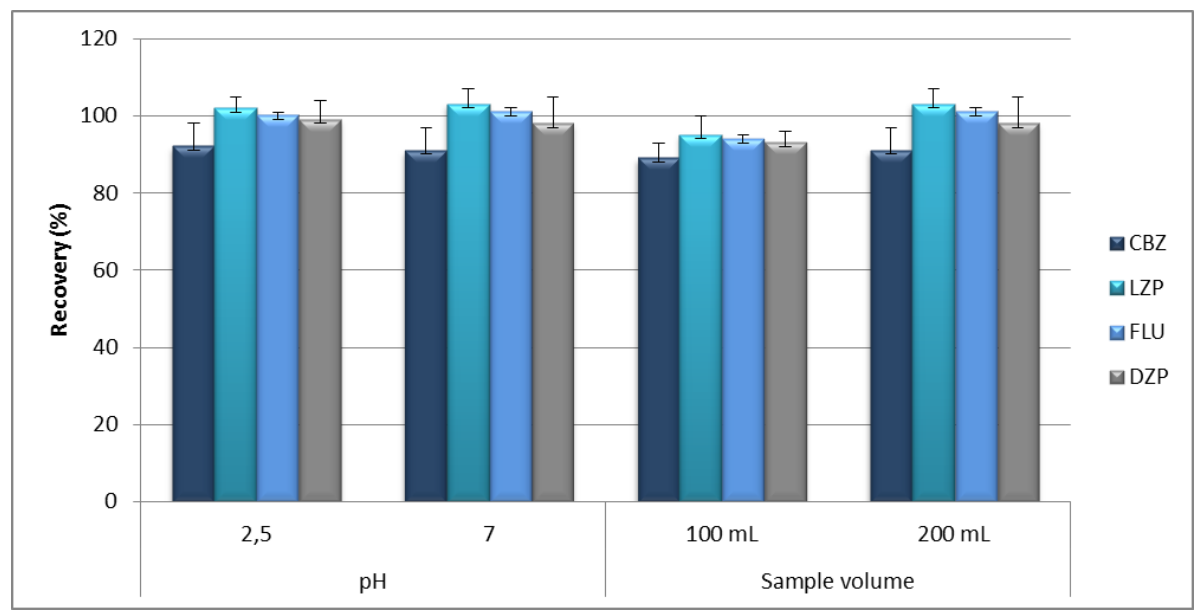

Figure 1. Recoveries of antidepressants obtained for different $\mathrm{pH}$ and sample volume

Recovery values of antidepressants for different fortification levels are given in Table 3. Recoveries ranged from 90 to $95 \%(S D<6)$ for $100 \mathrm{ng} \mathrm{l}^{-1}$ fortification concentration. Comparable recoveries were also determined $500 \mathrm{ng} \mathrm{l}^{-1}$ fortification concentration (89-100\%, $\mathrm{SD}<7)$ and $1000 \mathrm{ng} \mathrm{l}^{-1}$ fortification concentration (91-103\%, $\mathrm{SD}<8)$. The recovery values obtained for different analyte concentration were not significantly different $(p>0.05)$.

Table3. The recoveries of antidepressants for different fortification levels

\begin{tabular}{|c|c|c|c|c|c|c|}
\hline \multirow{3}{*}{ Analytes } & \multicolumn{6}{|c|}{ Spiked in ultrapure water } \\
\hline & \multicolumn{2}{|l|}{$100 \mathrm{ng} \mathrm{l}^{-1}$} & \multicolumn{2}{|c|}{$500 \mathrm{ng} \mathrm{l}^{-1}$} & \multicolumn{2}{|c|}{$1000 \mathrm{ng} \mathrm{l}^{-1}$} \\
\hline & Relative recovery (\%) & $\operatorname{RSD}(n=3)$ & Relative recovery (\%) & $\operatorname{RSD}(n=3)$ & Relative recovery (\%) & $\operatorname{RSD}(n=3)$ \\
\hline CBZ & 90 & 6 & 100 & 4 & 91 & 6 \\
\hline LZP & 94 & 4 & 98 & 5 & 103 & 4 \\
\hline FLU & 90 & 6 & 89 & 7 & 101 & 8 \\
\hline DZP & 95 & 5 & 93 & 5 & 98 & 7 \\
\hline
\end{tabular}

The pre-treatment procedure and matrix effects of samples on antidepressants extraction were also investigated. Figure 2 summarize recovery values obtained from pretreatment and matrix effects. The recovery values obtained for the nylon membrane filter $(0.45 \mu \mathrm{m}$ pore diameter) were between 87 and $100 \%(S D<7)$ while the recovery values for the glass fiber filters $(1.2 \mu \mathrm{m}$ pore diameter $)$ were between 89 and $96 \%(S D<8)$. The recovery values were obtained between $91-103 \%(S D<6)$ for ultrapure water, $91-97 \%(S D<8)$ for the influent and $89-96 \%(S D<7)$ for the effluent. As a result of the extractions, pretreatment and matrix have not got negative effect on extraction.

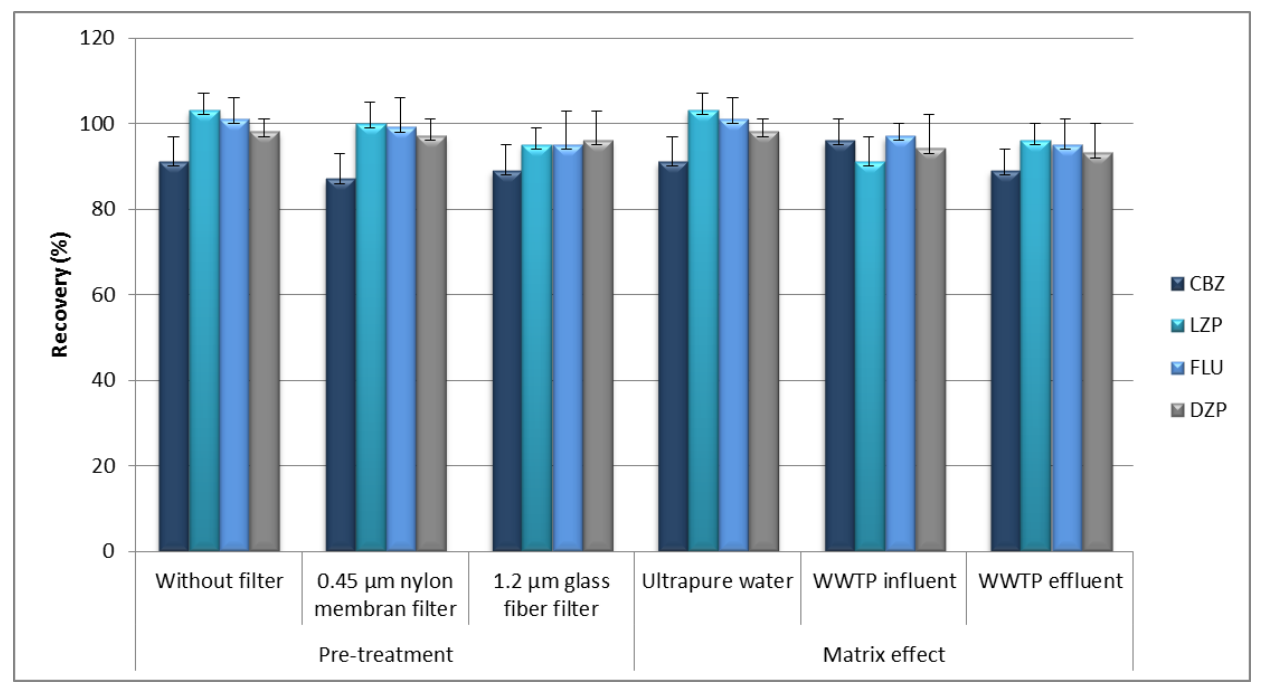

Figure 2. The effects of pre-treatment and matrix on recoveries of antidepressants 
The recovery values obtained for the antidepressants in literature are given in Table 4.

Verlicchi et al., (2012) investigated pharmaceutical in the influent, effluent and hospital wastewater. Samples were extracted using SPE with Oasis HLB cartridge and analyses were performed by LC-MS/MS. $100 \mathrm{ml}$ influent samples and $200 \mathrm{ml}$ effluent samples were used for analyses. Gros et al., (2006) developed analytical method with SPE and LCMS/MS. $200 \mathrm{ml}$ of effluent and $100 \mathrm{ml}$ of influent were used. The $\mathrm{pH}$ of the sample was adjusted as a neutral $\mathrm{pH}$. Grujic et al., (2009) was used Oasis HLB cartridge for SPE of surface, ground and wastewater samples. Sample volume was $100 \mathrm{ml}$ and sample $\mathrm{pH}$ was adjusted 3. Method for the simultaneous determination of 24 pharmaceuticals was developed. Good recoveries ( $\geq 70 \%$ ) were observed for all target pharmaceuticals when extraction was performed using Chromabonds HR-X cartridges under acidic condition $(\mathrm{pH}=2) .250 \mathrm{ml}$ of wastewater sample and $500 \mathrm{ml}$ of surface water sample were used (Han Tran et al., 2013). The recovery values for antidepressants determined in this study were comparable with results determined in the literature.

Table 4. The recoveries obtained for the antidepressants in literature (\%)

\begin{tabular}{|c|c|c|c|c|}
\hline Analytes & Surface water & WWTP influent & WWTP effluent & References \\
\hline \multirow{5}{*}{ CBZ } & b93 \pm 1 & ${ }^{\mathrm{a}} 145 \pm 8$ & ${ }^{\mathrm{a}} 111 \pm 7$ & \multirow{13}{*}{$\begin{array}{l}{ }^{\mathrm{a} V} \text { Verlicchi et al., } 2012 \\
\text { bGros et al., } 2006 \\
{ }^{\mathrm{c}} \text { Grujic et al., } 2009 \\
{ }^{\mathrm{d}} \text { Han Tran et al., } 2013 \\
\text { eThis study }\end{array}$} \\
\hline & ${ }^{\mathrm{b}} 67 \pm 6$ & b98 \pm 3 & ${ }^{b} 97 \pm 5$ & \\
\hline & c98 & ${ }^{\mathrm{b}} 105 \pm 10$ & b93 \pm 12 & \\
\hline & ${ }^{\mathrm{d}} 101 \pm 1.3$ & ${ }^{d} 101.4 \pm 4.4$ & & \\
\hline & & e $96 \pm 5$ & e $89 \pm 5$ & \\
\hline \multirow{2}{*}{ DZP } & c93 & ${ }^{\mathrm{a}} 103 \pm 3$ & a $59 \pm 16$ & \\
\hline & & e $94 \pm 8$ & e $93 \pm 7$ & \\
\hline \multirow{4}{*}{ FLU } & ${ }^{b} 105 \pm 6$ & ${ }^{\mathrm{a}} 109 \pm 9$ & ${ }^{\mathrm{a}} 107 \pm 6$ & \\
\hline & b74 \pm 12 & ${ }^{b} 108 \pm 4$ & ${ }^{b} 60 \pm 2$ & \\
\hline & & ${ }^{b} 67 \pm 12$ & b74 \pm 2 & \\
\hline & & ${ }^{\mathrm{e}} 97 \pm 3$ & $\mathrm{e} 105 \pm 6$ & \\
\hline \multirow{2}{*}{ LZP } & ${ }^{\mathrm{c} 102}$ & ${ }^{\mathrm{a}} 91 \pm 1$ & a $98 \pm 12$ & \\
\hline & & ${ }^{\mathrm{e}} 91 \pm 6$ & e $96 \pm 4$ & \\
\hline
\end{tabular}

\subsection{Concentration of Antidepressants in Influent and Effluent}

Antidepressants were detected Konya Wastewater Treatment Plant influent and effluent by developed analytical method. Figure 3 shows the range of concentrations of antidepressants measured at the influent and the effluent samples. While CBZ was determined between $6.35 \mathrm{ng} \mathrm{l}^{-1}$ and $135.6 \mathrm{ng} \mathrm{l}^{-1}$ in the influent samples, CBZ was determined between $<\mathrm{dl}$ and $245.13 \mathrm{ng} \mathrm{l}^{-1}$ in the effluent samples. DZP were not determined in the influent samples. However, DZP in effluent samples was determined as $<\mathrm{dl}-0.21 \mathrm{ng} \mathrm{l}^{-1}$. FLU in the influent samples varied from $<\mathrm{dl}$ to $2.6 \mathrm{ng} \mathrm{l}^{-1}$, and in the effluent samples from $<\mathrm{dl}-2.7 \mathrm{ng} \mathrm{l}^{-1}$. LZP in the influent samples varied from $<\mathrm{dl}$ to $4.8 \mathrm{ng} \mathrm{l}^{-1}$ and in the effluent from $<\mathrm{dl}-2.2 \mathrm{ng} \mathrm{l}^{-1}$. The results showed that CBZ was the most frequently found in the influent and effluent and it was determined in all months. CBZ is used control of grand mal and psychomotor epilepsy and it is also effective in the treatment of trigeminal neuralgia. CBZ is much consumed antidepressant in worldwide. Approximately $28 \%$ of orally administered CBZ is unchanged and subsequently discharged through the feces (RxList, 2006). Also, its distribution coefficient between water and sludge $(\mathrm{Kd})$ is $1.2 \mathrm{l} / \mathrm{kg}_{\mathrm{ss}}$, so it is hardly absorbed on sludge. Therefore, CBZ remains in aqueous phase (Ternes et al., 2004; Zhang et al., 2008). FLU and LZP after CBZ were the most frequently detected compounds. They were determined in both the influent and effluent samples at January and February. However, DZP was not detected in the influent; it was detected only in the effluent sample taken from February. The highest concentrations of investigated antidepressants were detected in August, September and October in wastewater samples. Use of antidepressants may increase in these months because seasonal affective disorder is a combination of biologic and mood disturbances, typically occurring in the autumn and winter. Also, the microbial activity and biological reactions are reduced due to low temperatures in winter leading to increased concentrations of pharmaceuticals in the wastewater.

Yuan et al., (2013) found LZP at concentration $205 \mathrm{ng} \mathrm{l}^{-1}$ in the influent, $294 \mathrm{ng} \mathrm{l}^{-1}$ in effluent. FLU was measured concentration at $120.7 \mathrm{ng} \mathrm{l}^{-1}$ in the influent, < $<\mathrm{dl}$ in effluent (Silva et al., 2014). Lajeunesse et al., (2012) reported that the concentrations of the antidepressants, including CBZ, FLU, LZP in the influent wastewater ranged from $<$ dl to $3124 \mathrm{ng} \mathrm{l}^{-1}$, and effluent wastewater ranged from 6.6 to $2956 \mathrm{ng} \mathrm{l}^{-1}$. The antidepressants DZP and LZP were quantified at concentrations varying from $<\mathrm{dl}$ to $250 \mathrm{ng} \mathrm{l}^{-1}$ in the influent and effluent wastewater (Verlicchi et al., 2012). FLU was detected in treated wastewater at concentrations up to $142 \mathrm{ng} \mathrm{l}^{-1}$ and surface water at concentrations up to $46 \mathrm{ng} \mathrm{l}^{-1}$ (Metcalfe et al., 2003). Residues of CBZ were found, in the concentration range 12$15 \mathrm{ng} \mathrm{l}^{-1}$ (Grujic et al., 2009). Heberer, (2012) reports CBZ concentrations of up to $1075 \mathrm{ng} \mathrm{l}^{-1}$ surface water samples. W. Kolpin et al., (2002) detected FLU in streams at concentrations up to $12 \mathrm{ng} \mathrm{l}^{-1}$. CBZ was reported high concentration in literature. Different concentration 
between this study and literature may depend upon various factors such as production, consumption, excretion, solar irradiance, precipitation, temperature, treatment technologies.

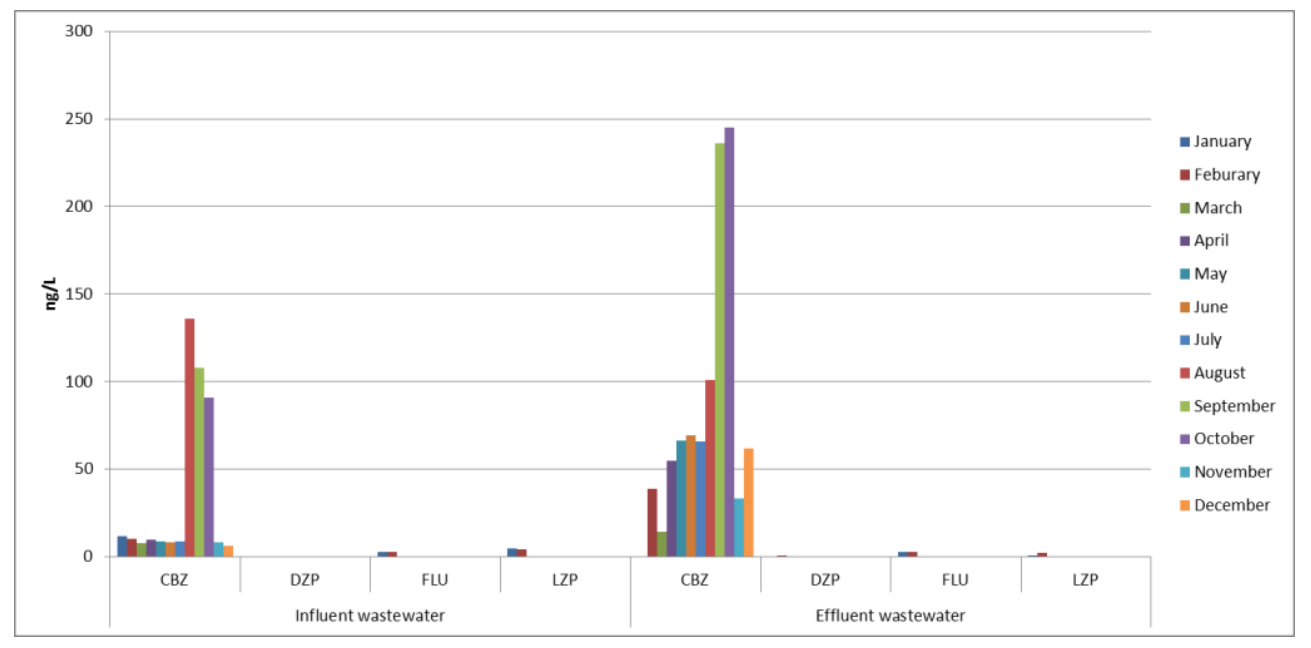

Figure 3. Concentration of antidepressants in the influent and effluent WWTP $\left(\mathrm{ng} \mathrm{l}^{-1}\right)$

\subsection{Removal of antidepressants in Konya Wastewater Treatment Plant}

Conventional treatment methods are applied at Konya Urban Wastewater Treatment Plant. Konya Urban Wastewater Treatment Plant have screens, aerated grit and grease tanks, primary clarifiers, aeration tanks, final sedimentation tanks, sludge thickeners, anaerobic digesters, ultraviolet disinfection units. Effluent samples were taken outlet of final sedimentation tank. Removals of antidepressants in treatment plant were calculated with detected concentration. Removals of antidepressants were observed only at January, February and August. Removals of antidepressants were not detected in March, April, May, June, July, August, September, October, November, and December. The calculated removal efficiencies for CBZ, FLU, LZP were $100 \%, 2.4 \%$ and $89.1 \%$ in January, respectively. The observed removal efficiency of LZP was calculated to $46.9 \%$ in February. CBZ was removed at $25.7 \%$ rates. The low removal rates of antidepressants were observed in conventional WWTP due to resistance to biodegradation at low concentrations and less attachment to sludge. The removal of CBZ was reported between 7\% and $35 \%$ in conventional activated sludge (Radjenovic et al., 2007; Santos et al., 2009; Kreuzinger et al., 2004; Suárez et al., 2005). Suárez et al., (2005) studied the removal of DZP during conventional activated sludge treatment plant and they observed $8 \%$ removal. Removal of FLU in conventional treatment plant was reported as 33\%-54\% by Zorita et al., 2009 and Radjenovic et al., 2009.

The variation in the removal rates of antidepressants during treatments observed in different studies may be a results of different factors such as different wastewater characteristics, operational conditions and treatment technologies used, sampling procedures (Jelic et al., 2012).

\subsection{Potential Ecotoxicological Risk}

Another objective of this study is to estimate the potential risk of Konya Wastewater Treatment Plant effluent. Risk assessment has been carried out with $\mathrm{HQ}$ methods.

Measured environmental concentration (MEC)/Predicted No Effect Concentration (PNEC) ratio is $\mathrm{HQ}$ value. PNEC values were obtained with aquatic toxicity data of three different species (fish, Daphnia magna and algae) from different trophic levels that represent the aquatic ecosystem (Commission of the European Communities, 1996). If $\mathrm{HQ}$ values are below 0.1 , there is not adverse effect which means insignificant risk. If $\mathrm{HQ}$ values are between 0.1 and 1 , the risk is low, If $\mathrm{HQ}$ values are between 1 and 10 , the risk is moderate and HQ values are above 10, the risk is high (Commission of the European Communities, 1996; Mendoza, 2015). Figure 4 shows calculated HQ (MEC/PNEC) values. $\mathrm{HQ}$ values calculated with FLU concentration of January and February samples for Algae are above 0.1 , so there is low risk. $\mathrm{HQ}$ values of CBZ, DZP, FLU and LZP compounds were calculated below 0.1 for species (fish, Daphnia magna and algae) in others months, March, April, May, June, July, August, September, October, November, December, meaning that no adverse effects can be expected. Therefore, there is insignificant risk for $C B Z$, DZP, FLU and LZP compounds.

Jelic et al., (2012) carried out risk assessment for WWTP effluent wastewater. RQ (Risk quotient, MEC/PNEC) for the three trophic levels (fish, algae and Daphnia magna) was detected less than one. Risk assessment was evaluated, when the RQ is below 1 , the risk is considered low. They are reported indicating no direct risk for the aquatic environment. Verlicchi, (2012) evaluated potential environmental risk assessment for two different sized hospitals and the influent and effluent of the municipal treatment plant Italy. The potential risk was assessed by means of their risk quotient values. A high risk was found for FLU compound in the influent and the effluent of the municipal WWTP. 


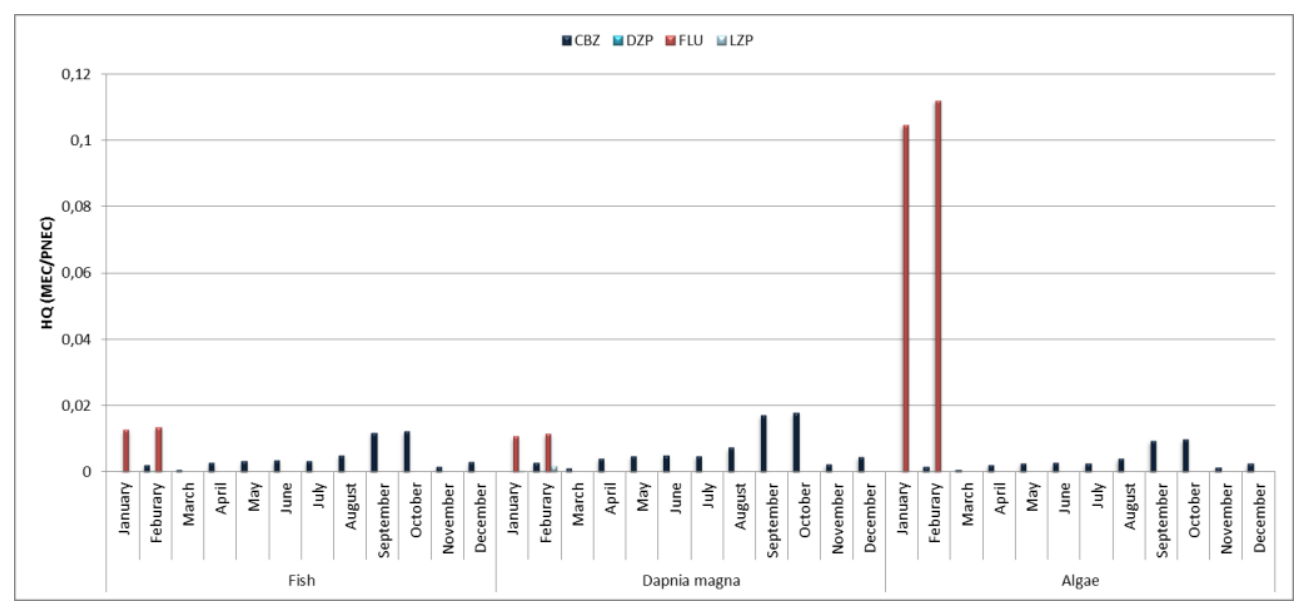

Figure 4. $\mathrm{HQ}$ values determined for effluent wastewaters

\section{Conclusions}

In this paper, antidepressant concentrations were investigated in the influent and effluent samples taken from taken Konya Wastewater Treatment Plant. Analyses of antidepressants were performed with SPE and LC$\mathrm{MS} / \mathrm{MS}$. HQ method was used for risk evaluation. Antidepressant concentrations in the influent varied from $<$ dl-135 $\mathrm{ng} \mathrm{l}^{-1}$ and in the effluent from $<$ dl-245 $\mathrm{ng} \mathrm{l}^{-1}$. Low risk was determined at samples taken January and February samples.

Antidepressants have been detected in surface, waste, drinking and ground waters at $\mathrm{ng} \mathrm{l}^{-1}$ and $\mu \mathrm{g}^{-1}$ levels. However there is not enough study about antidepressants. Antidepressants should be monitored in the environment; there should be more research on risks posed by them.

Acknowledgments - The study was supported by TUBA-GEBIP project and Scientific Research Projects Coordination Unit of Necmettin Erbakan University (Project No: 151419001and 151219004).

\section{References}

Calisto V. and Esteves V.I. (2009), Review, Psychiatric pharmaceuticals in the environment, Chemosphere, 77, 1257-1274.

Commission of the European Communities (1996) Technical guidance document in support of commission directive 93/67/ EEC on risk assessment for new notified substances. Part II, environmental risk assessment. Luxembourg: Office for official publication of the European Communities.

Fent K., Weston A.A. and Caminada D. (2006), Ecotoxicology of human pharmaceuticals, Aquatic Toxicology, 76, 122.

Gros M., Petrović M. and Barceló D. (2006), Development of a multi-residue analytical methodology based on liquid chromatography-tandem mass spectrometry (LC-MS/MS) for screening and trace level determination of pharmaceuticals in surface and wastewaters, Talanta, 70, 678-690.

Grujić S., Vasiljević T. and Laušević M., (2009), Determination of multiple pharmaceutical classes in surface and ground waters by liquid chromatography-ion trap-tandem mass spectrometry, Journal of Chromatography A, 1216, 4989-5000.
Han Tran N., Hu J. and Leong Ong S. (2013), Simultaneous determination of PPCPs, EDCs, and artificial sweeteners in environmental water samples using a single-step SPE coupled with HPLC-MS/MS and isotope dilution, Talanta, 113,82-92.

Heberer T. (2002), Occurrence, fate, and removal of pharmaceutical residues in the aquatic environment: a review of recent research data, Toxicology Letters, 131(1-2), 5-17.

Jelic A., Fatone F., Di Fabio S., Petrovic M., Cecchi F. and Barcelo D. (2012), Tracing pharmaceuticals in a municipal plant for integrated wastewater and organic solid waste treatment, Science of the Total Environment, 433, 352-361.

Kreuzinger N., Clara M., Srenn B. and Kroiss H. (2004), Relevance of the sludge retention time (SRT) as design criteria for wastewater treatment plants for the removal of endocrine disruptorsB and pharmaceutical from wastewater, Water Science and Technology, 50, 149-156.

Kolpin D.W., Furlong E.T., Meyer M.T., Thurman E.M., Zaugg S.D., Barber L.B., and Buxton H.T. (2002), Pharmaceuticals, hormones, and other organic wastewater contaminants in US streams, 1999-2000: a national reconnaissance, Environmental Science and Technology, 36, 1202-1211.

Lajeunesse A., Smyth S.A., Barclay K., Sauve S. and Gagnon C. (2012), Distribution of antidepressant residues in wastewater and biosolids following different treatment processes by municipal wastewater treatment plants in Canada, Water Research, 46, 5600-5612.

Mendoza A., Aceña J., Pérez S., Lópezde Alda M., Barceló D., Gil A. and Valcárcel Y. (2015), Pharmaceuticals and iodinated contrast media in a hospital waste- water: A case study to analyse their presence and characterise their environmental risk and hazard, Environmental Research, 140, 225-241.

Metcalfe C.D., Miao X.S., Koenig B.G. and Struger J. (2003), Distribution of acidic and neutral drugs in surface waters near sewage treatment plants in the lower Great Lakes, Canada, Environmental Toxicology and Chemistry, 22(12), 2881-2889.

Radjenovic J., Petrovic M. and Barcelo D. (2007), Analysis of pharmaceuticals in wastewater and removal using a membrane bioreactor, Analytical and Bioanalytical Chemistry, 387, 1365-1377.

Radjenovic J., Petrovic M. and Barceló D. (2009), Fate and distribution of pharmaceuticals in wastewater and sewage sludge of the conventional activated sludge (CAS) and 
advanced membrane bioreactor (MBR) treatment, Water Research, 43, 831-841.

Richardson S.D. and Ternes T.A. (2005), Water analysis: emerging contaminants and current issues, Analytical Chemistry, 77(12), 3807-3838.

RxList, 2006, The Internet Drug Index. <http://www.rxlist.com>.

Santoke H., Song W., Cooper W.J. and Peake B.M. (2012), Advanced oxidation treatment and photochemical fate of selected antidepressant pharmaceuticals in solutions of Suwannee River humic acid, Journal of Hazardous Materials, 217- 218, 382- 390.

Santos J.L., Aparicio I., Callejon M. and Alonso E. (2009), Occurrence of pharmaceutically active compounds during 1year period in wastewater from four wastewater treatment plants in Seville (Spain), Journal of Hazardous Materials, 164, 1509-1516.

Schultz M.M. and Furlong E.T. (2008), Trace analysis of antidepressant pharmaceuticals and their select degradates in aquatic matrixes by LC/ESI/MS/MS, Analytical Chemistry, 80, 1756-1762.

Silva L.J.G., Pereira A.M.P.T., Meisel L.M., Lino C.M. and Pena A. (2014), A one-year follow-up analysis of antidepressants in Portuguese wastewaters: Occurrence and fate, seasonal influence and risk assessment, Science of the Total Environment, 490, 279-287

Sim W.J., Lee J.W. and Oh J.E. (2010), Occurrence and fate of pharmaceuticals in wastewater treatment plants and rivers in Korea, Environmental Pollution, 158, 1938-1947.

Suárez S., Ramil M., Omil F. and Lema J.M. (2005), Removal of pharmaceutically active compounds in nitrifying-denitrifying plants, Water Science and Technology, 52, 9-14.

Ternes T.A., Bonerz M., Herrmann N., Löffler D., Keller E., Bago B., and Alder A.C. (2005), Determination of pharmaceuticals, iodinated contrast media and musk fragrances in sludge by LC tandem MS and GC/MS, Journal of Chromatography A, 1067, 213-223.

Ternes T.A., Bonerz M. and Schmidt T. (2001), Determination of neutral pharmaceuticals in wastewater and rivers by liquid chromatography-electrospray tandem mass spectrometry, Journal of Chromatography A, 938(1-2), 175-185.

Van der Ven K., Keil D., Moens L.N., Hummelen P.V., Van Remortel P., Maras M. and De Coen W. (2006), Effects of the antidepressant mianserin in zebrafish: molecular markers of endocrine disruption, Chemosphere, 65, 1836-1845.

Verlicchi P., Al Aukidy M., Galletti A., Petrovic M. and Barceló D. (2012), Hospital effluent: Investigation of the concentrations and distribution of pharmaceuticals and environmental risk assessment, Science of the Total Environment, 430, 109-118.

Yuan S., Jiang X., Xia X., Zhang H. and Zheng S. (2013), Detection, occurrence and fate of 22 psychiatric pharmaceuticals in psychiatric hospital and municipal wastewater treatment plants in Beijing, China, Chemosphere, 90, 2520-2525.

Zhang Y., Geißen S.U. and Gal C. (2008), Carbamazepine and diclofenac: Removal in wastewater treatment plants and occurrence in water bodies, Chemosphere, 73, 1151-1161

Zorita S., Martensson L. and Mathiasson L. (2009), Occurrence and removal of pharmaceuticals in municipal sewage treatment system in the south of Sweden, Science of the Total Environment, 407, 2760-2770. 